\title{
Itraconazole and thiophanate-methyl fail to clear tadpoles naturally infected with the hypervirulent lineage of Batrachochytrium dendrobatidis
}

\author{
Andrés Fernández-Loras ${ }^{1}$, Bárbara Martín-Beyer ${ }^{1}$, Trenton W. J. Garner ${ }^{2,3}$, Jaime Bosch ${ }^{1,4, *}$ \\ ${ }^{1}$ Museo Nacional de Ciencias Naturales-CSIC, 28006 Madrid, Spain \\ ${ }^{2}$ Institute of Zoology, Zoological Society of London, Regent's Park, London NW1 4RY, UK \\ ${ }^{3}$ Unit for Environmental Research and Management, North-West University, Potchefstroom \\ 2520, South Africa \\ ${ }^{4}$ Centro de Investigación, Seguimiento y Evaluación, Parque Nacional de la Sierra de \\ Guadarrama, 28740 Rascafría, Spain
}

*Corresponding author: bosch@mncn.csic.es

ABSTRACT: The emerging infectious disease chytridiomycosis, caused by the fungus Batrachochytrium dendrobatidis, is a major driver pushing many amphibian species to the brink of extinction. Substantial efforts to develop effective protocols that use antifungal drugs have had notable success. Here, we used the antifungal agents itraconazole and thiophanatemethyl, singly and in combination, in an attempt to treat common midwife toad Alytes obstetricans larvae naturally infected with the globalized hypervirulent lineage of $B$. dendrobatidis. Despite the successful use of itraconazole in a closely related species (A. muletensis), our results show that these antifungal treatments are not always effective and that full clearance of animals cannot be assumed following treatment.

KEY WORDS: Chytridiomycosis · Chytrid fungus · Alytes obstetricans · Antifungal agent

\section{INTRODUCTION}

Amphibians are the most threatened and rapidly declining vertebrate class, and the emerging infectious disease chytridiomycosis, caused by the fungus Batrachochytrium dendrobatidis $(B d)$, is responsible for globally widespread declines (Stuart et al. 2004). The widespread and hypervirulent global panzootic lineage $(B d \mathrm{GPL})$ is responsible for most cases of lethal chytridiomycosis (Farrer et al. 2011).

The link between the international trade in amphibians and transmission of chytridiomycosis has spurred efforts to develop methods for eliminating infections in captive settings, not all of which have involved the use of chemical substances. For example, in vitro $B d$ growth trials have illustrated how temperatures above $30^{\circ} \mathrm{C}$ can kill the cultured pathogen, and in vivo trials have extended this to viable infections (Woodhams et al. 2003).

Unfortunately, most abiotic environments that are likely to be hostile to $B d$ are also likely to be hostile to the majority of host species and may compromise their health and welfare (Garner et al. 2016).

Parallel efforts to develop treatments for $B d$ infections have examined the efficacy of antifungal drugs already in use by the veterinary community. Successful applications of chloramphenicol and malachite green combined with formalin have been reported (Bishop et 
al. 2009, Young et al. 2012). However, their potential side effects, risks to human and animal health and legal restrictions likely preclude a more general, international application of these substances (Holden et al. 2014). Benzalkonium chloride $\left(\mathrm{F} 10^{\odot}\right)$ has also been used successfully (Barrows et al. 2010), but other studies have questioned both the efficacy and general applicability of this disinfectant (Berger et al. 2009, de Jong et al. 2018).

Several encouraging studies have focussed on 2 other substances: thiophanate-methyl (TM), predominantly applied environmentally as a pesticide, and itraconazole (ITZ), a common veterinary and medical antifungal. Hanlon et al. (2012) showed that TM cleared infection and increased amphibian growth metrics, suggesting its transferability to other host species and habitat settings. ITZ is a first-generation systemic triazole antifungal drug widely used in zoos and other ex situ captive breeding conservation programmes to treat chytridiomycosis. In vivo application of weak concentrations of ITZ have been used repeatedly and successfully to clear infections in several species (Forzán et al. 2008, Garner et al. 2009, Tobler \& Schmidt 2010, Brannelly et al. 2012, Jones et al. 2012). These results are encouraging, not least because the only successful eradication of $B d$ in the wild to date (Bosch et al. 2015) applied a combination of ITZ and environmental disinfection, while other strategies have not had similar success (Berger et al. 2010, Woodhams et al. 2012, Baitchman \& Pessier 2013). However, these findings need to be put into context. While ITZ can be used for short periods of time ( $7-11 \mathrm{~d})$ on a daily basis $(5-10 \mathrm{~min}$ baths) and is considered low risk to humans, the commercially available aqueous solution contains hydrochloric acid and is extremely acidic. A recent study has highlighted mortality effects associated with ITZ exposure experienced by toads subsequently subjected to cold stress (Loyau et al. 2016), and others have raised the possibility that ITZ may impair amphibian health (Garner et al. 2009). While no such data for amphibians exist for TM, it is classified as a moderate ecotoxicological risk to fish and invertebrates (pesticide properties database of the University of Hertfordshire).

Here we used different concentrations and durations of ITZ and TM to treat common midwife toad Alytes obstetricans tadpoles suffering from natural infections with BdGPL. Ours aims were to test survival after the treatments as well as the effectiveness of the antifungals in reducing or completely clearing infections.

\section{MATERIALS AND METHODS}

Alytes obstetricans larvae were collected from different locations throughout Spain (Teruel, Zamora, Peñalara Massif and Ibón Acherito) and housed individually in boxes containing $750 \mathrm{ml}$ of water in a temperature-controlled room. Tadpoles were fed twice per week and water was changed every 3 d. Before treatments, oral swabs (MW 100-100, Medical Wire \& Equipment) were taken and weights were measured.

We used different ITZ concentrations (Itrafungol, except for experiment ITZ.3, in which Canadiol was used; ESTEVE) in daily baths of 5 or 10 min (Table 1). For TM experiments, we also modified the number of days the treatment was given throughout the different experiments. In ITZ experiments, water was replaced every day after baths, while in TM experiments, water was replaced every $3 \mathrm{~d}$ and then the drug was re-applied. For each drug, treatments sharing a number code shared the same control group of 20 animals. After 15 $\mathrm{d}$, surviving animals in each treatment group were euthanized with an overdose of tricaine methanesulfonate buffered with $\mathrm{NaHCO}_{3}$, and whole tadpoles' mouths were analysed.

We used a CFX96 qPCR thermocycler (Bio-Rad) for $B d$ detection and DNA quantification. Each plate included samples, a negative control and 4 different standards 
ranging from 100 to $0.1 B d$ genome equivalents in duplicate. Samples were scored as positives when both replicates were $\geq 0.1$ and the amplification curves had a sigmoidal shape.

When possible, infection loads and prevalence of infection were compared between pre- and post-treatment stages in experimental animals using the Wilcoxon-Mann-Whitney and Pearson tests. We used Fisher's exact tests to test for differences in survival between control and treatment groups. All animal experiments were conducted in compliance with the Directive 2010/63/EU for the protection of animals used for scientific purposes in facilities of the regional government and with permission from the relevant and competent authorities.

\section{RESULTS}

No ITZ-only treatment achieved complete $B d$-clearance (Fig。 1). High tadpole survival rates were obtained in some, but not all of the experiments (ITZ.1-2), but full clearance combined with high survival was never achieved in any of the ITZ-only experiments (ITZ.16). However, statistically significant decreases in prevalence of infection and average infection loads after treatments were detected in several of the ITZ-only treatments (prevalence: ITZ.1A: $\chi^{2}=32.211, \mathrm{p}<0.0001$; ITZ.1B: $\chi^{2}=13.298, \mathrm{p}=0.0003$; ITZ.1C: $\chi^{2}=$ 28.558, $<<0.0001$; ITZ.2A: $\chi^{2}=9.642, p=0.0019$; ITZ.2B: $\chi^{2}=9.642, p=0.0019$; ITZ.8B: $\chi^{2}=9.975, \mathrm{p}=0.0016$; infection load: ITZ.1A: $Z=5.401, \mathrm{p}<0.0001 ;$ ITZ.1B: $Z=4.516, \mathrm{p}<$ 0.0001; ITZ.1C: $Z=5.518, \mathrm{p}<0.0001$; ITZ.2A: $Z=3.646, \mathrm{p}=0.0003$; ITZ.2B: $Z=3.677$, p $=0.0002$; ITZ.8B: $Z=1.488, \mathrm{p}=0.1368)$. TM on its own also failed to fully clear $B d$ infections. Nonetheless, we detected a statistically significant decrease in prevalence and average infection loads in almost all TM-only treatment trials (prevalence: TM.1: $\chi^{2}=28.972$, p < 0.0001; TM.3: $\chi^{2}=10.909, p=0.0010$; TM.4: $\chi^{2}=14.227, p=0.0002$; infection load: TM.1: $Z=5.396, \mathrm{p}<0.0001 ;$ TM.2: $Z=4.815$, p < 0.0001; TM.3: $Z=4.690, \mathrm{p}<0.001$; TM.4: $Z=3.787, \mathrm{p}=0.0002$ ). Combined treatments reduced infection loads (TM-ITZ.1A: $Z$ $=2.595, \mathrm{p}=0.0095$; TM-ITZ.1B: $Z=2.212, \mathrm{p}=0.0269)$ but without a concurrent reduction in prevalence (TM-ITZ.1A: $\chi^{2}=1.667, p=0.1967$; TM-ITZ.1B: $\chi^{2}=1.236, p=0.2662$ ).

Survival was inconsistent across experiments. In ITZ experiments where concentrations exceeded $0.01 \%$, we detected significantly increased mortality (experiments ITZ.3-5, ITZ.7-8: $p<0.0001$; ITZ.6: $p<0.05)$. This was not the case for experiments where we exposed animals to increasing concentrations of TM, although we did detect significantly decreased survival in the experiment involving the weakest solution of TM (TM.1: $\mathrm{p}<0.05$ ).

All significant tests remained significant after Bonferroni sequential correction except TM-ITZ.1B for infection load and ITZ.6 and TM.1 for survival.

\section{DISCUSSION}

This study shows that serial treatments of naturally BdGPL-infected ( Alytes obstetricans larvae with concentrations of antifungals comparable to those that cleared infections in other species were ineffective. ITZ appeared to be more effective at reducing loads in ITZ-only experiments but not in combined treatments (Fig. 1). Further, concentrations of ITZ previously used to comprehensively eliminate infections in a congener were ineffective at achieving clearance in wild-captured common midwife toads (Garner et al. 2009, Bosch et al. 2015). We cannot say why this is so, but failure to clear infections is unlikely related to developmental stage, as a previous study of ITZ using post-metamorphic A. obstetricans also failed to achieve comprehensive clearance (Loyau et al. 2016). Irrespective of the antifungal agent and species of Alytes, ex situ application of antifungals offers transient effects at best in this genus (Geiger et al. 2017), which is mirrored in field trials of ITZ in other species (Hudson et al. 2016). More importantly, while ITZ has 
sometimes proven to be an effective clinical treatment in captive settings (Forzán et al. 2008, Garner et al. 2009, Tobler \& Schmidt 2010, Brannelly et al. 2012, Jones et al. 2012), our study illustrates how efficacy in some cases does not always transfer to others.

The failure of TM and mixed treatments to clear infection further highlights this lack of transferability, although Hanlon et al. (2012) press-applied TM continuously for up to 60 days, at least 4 times longer than our treatments. We saw no evidence of a cost due to increasing length of exposure to TM. Increasing the length of application may yield better results than the limited reduction of prevalence and load we observed in our shorter exposure periods (Fig. 1).

We did observe a significant effect with increased concentration of ITZ on posttreatment survival, and once concentrations exceeded $0.01 \%$, tadpole survival dropped to zero. The short-term and low-concentration impacts we report here likely represent one of the most severe outcomes for the application of ITZ, but we cannot attribute impacts to the drug, as the commercial solution also contains other potentially hazardous components that increased in concentration along with the ITZ. Furthermore, the impacts may be cumulative rather than direct: exposure to $B d$ can immunosuppress common midwife tadpoles and otherwise compromise their health (Fernández-Loras et al. 2017). These types of costs can result in increased mortality in their own right, and may very well increase the likelihood of mortality associated with exposure to any further stressor like treatment with an antifungal or exposure to an acidic solution. Whatever the mechanism behind the effect on survival, our results do indicate that application of ITZ solutions exceeding $0.01 \%$ should be avoided for treatment of $B d$ infections in larval amphibians.

Our study adds to the growing literature examining field and captive applications of chemical treatments to control the impacts of $B d$ in amphibians (e.g. Martel et al. 2011). Unfortunately, our findings do more to illustrate the limitations of these approaches rather than provide more tools that can be applied toward mitigation of chytridiomycosis. While this message appears to be anything but optimistic, it does draw much needed attention to the fact that any approach developed for combating chytridiomycosis is unlikely to be widely transferable across amphibian species, and possibly across populations of the same species (Garner et al. 2016). Unfortunately, research on approaches for controlling the disease lags far behind the efforts to understand the ecology and evolution of the pathogen and how it interacts with hosts. This has to change.

Acknowledgements. We thank all the workers from Sierra de Guadarrama National Park and the molecular biology laboratory of MNCN, especially Pilar Ochoa. This research was conducted under permits of the Consejería de Medio Ambiente of Aragón, Castilla y León and Madrid, and supported by the Fundación BBVA. T.W.J.G. was supported by NERC Standard Grant NE/N009967/1.

<jrn>Baitchman EJ, Pessier AP (2013) Pathogenesis, diagnosis, and treatment of amphibian chytridiomycosis. Vet Clin North Am Exot Anim Pract 16:669-685 PubMed doi:10.1016/j.cvex.2013.05.009</jrn>

$<$ jrn>Barrows M, Koeppel K, Drake G (2010) The use of F10 as a treatment for bacterial and fungal disease in anurans. In: 2010 Proceedings: Association of Reptile and Amphibian Veterinarians, p 21-22</jrn> 
<jrn>Berger L, Speare R, Marantelli G, Skerratt LF (2009) A zoospore inhibition technique to evaluate the activity of antifungal compounds against Batrachochytrium dendrobatidis and unsuccessful treatment of experimentally infected green tree frogs (Litoria caerulea) by fluconazole and benzalkonium chloride. Res Vet Sci 87:106-110 PubMed doi:10.1016/j.rvsc.2008.11.005 </jrn>

<jrn>Berger L, Speare R, Pessier A, Voyles J, Skerratt LF (2010) Treatment of chytridiomycosis requires urgent clinical trials. Dis Aquat Org 92:165-174 PubMed

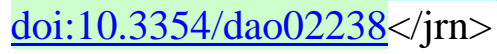

$<$ jrn>Bishop PJ, Speare R, Poulter R, Butler M and others (2009) Elimination of the amphibian chytrid fungus Batrachochytrium dendrobatidis by Archey's frog Leiopelma archeyi. Dis Aquat Org 84:9-15 PubMed doi:10.3354/dao02028</jrn>

$<$ jrn>Bosch J, Sanchez-Tomé E, Fernández-Loras A, Oliver JA, Fisher MC, Garner TW (2015) Successful elimination of a lethal wildlife infectious disease in nature. Biol Lett 11:20150874 PubMed doi:10.1098/rsbl.2015.0874</jrn>

<jrn>Brannelly LA, Richards-Zawacki CL, Pessier AP (2012) Clinical trials with itraconazole as a treatment for chytrid fungal infections in amphibians. Dis Aquat Org 101:95-104 PubMed doi: $10.3354 /$ dao02521 $</ j r n>$

<jrn>de Jong MS, van Dyk R, Weldon C (2018) Antifungal efficacy of F10SC veterinary disinfectant against Batrachochytrium dendrobatidis. Med Mycol 56:60-68 PubMed doi:10.1093/mmy/myx023</jrn>

$<$ jrn>Farrer RA, Weinert LA, Bielby J, Garner TW and others (2011) Multiple emergences of genetically diverse amphibian-infecting chytrids include a globalized hypervirulent recombinant lineage. Proc Natl Acad Sci USA 108:18732-18736 PubMed doi:10.1073/pnas.1111915108</jrn>

<jrn>Fernández-Loras A, Fernández-Beaskoetxea S, Arriero E, Fisher MC, Bosch J (2017) Early exposure to Batrachochytrium dendrobatidis causes profound immunosuppression in amphibians. Eur J Wildl Res 63:99 doi:10.1007/s10344-017-1161-y</jrn>

<jrn>Forzán MJ, Gunn H, Scott P (2008) Chytridiomycosis in an aquarium collection of frogs: diagnosis, treatment and control. J Zoo Wildl Med 39:406-411 PubMed doi:10.1638/2007-0091.1</jrn>

<jrn>Garner TWJ, Garcia G, Carroll B, Fisher MC (2009) Using itraconazole to clear Batrachochytrium dendrobatidis infection, and subsequent depigmentation of Alytes muletensis tadpoles. Dis Aquat Org 83:257-260 PubMed doi:10.3354/dao02008</jrn>

$<$ jrn>Garner TWJ, Schmidt BR, Martel A, Pasmans F and others (2016) Mitigating amphibian chytridiomycosis in nature. Philos Trans R Soc B 371:20160207 PubMed doi:10.1098/rstb.2016.0207</jrn>

$<$ jrn>Geiger CC, Bregnard C, Maluenda E, Voordouw MJ, Schmidt BR (2017) Antifungal treatment of wild amphibian populations caused a transient reduction in the prevalence of the fungal pathogen, Batrachochytrium dendrobatidis. Sci Rep 7:5956 PubMed doi:10.1038/s41598-017-05798-9</jrn>

$<$ jrn>Hanlon SM, Kerby JL, Parris MJ (2012) Unlikely remedy: fungicide clears infection from pathogenic fungus in larval southern leopard frogs (Lithobates sphenocephalus). PLOS ONE 7:e43573 PubMed doi:10.1371/journal.pone.0043573</jrn>

$<$ jrn>Holden WM, Ebert AR, Canning PF, Rollins-Smith LA (2014) Evaluation of amphotericin $\mathrm{B}$ and chloramphenicol as alternative drugs for treatment of 
chytridiomycosis and their impacts on innate skin defenses. Appl Environ Microbiol 80:4034-4041 PubMed doi:10.1128/AEM.04171-13</jrn>

<jrn>Hudson M, Young R, Lopez J, Martin L and others (2016) In-situ itraconazole treatment improves survival rate during an amphibian chytridiomycosis epidemic. Biol Conserv 195:37-45 doi:10.1016/j.biocon.2015.12.041</jrn>

<jrn>Jones MEB, Paddock D, Bender L, Allen JL, Schrenzel MD, Pessier AP (2012)

Treatment of chytridiomycosis with reduced-dose itraconazole. Dis Aquat Org 99:243249 PubMed doi:10.3354/dao02475 </jrn>

$<$ jrn>Loyau A, Cornuau JH, Clare FC, Schmeller DS (2016) Side effects of itraconazole on post-metamorphic Alytes obstetricans after a cold stress. Amphib-Reptil 37:345-357 doi:10.1163/15685381-00003064</jrn>

<jrn>Martel A, Van Rooij P, Vercauteren G, Baert K and others (2011) Developing a safe antifungal treatment protocol to eliminate Batrachochytrium dendrobatidis from amphibians. Med Mycol 49:143-149 PubMed doi:10.3109/13693786.2010.508185 </jrn>

$<$ jrn>Stuart SN, Chanson JS, Cox NA, Young BE, Rodrigues AS, Fischman DL, Waller RW (2004) Status and trends of amphibian declines and extinctions worldwide. Science 306:1783-1786 PubMed doi:10.1126/science.1103538</jrn>

$<$ jrn> Tobler U, Schmidt BR (2010) Within- and among-population variation in chytridiomycosis-induced mortality in the toad Alytes obstetricans. PLOS ONE 5:e10927 PubMed doi:10.1371/journal.pone.0010927</jrn>

$<$ jrn>Woodhams DC, Alford RA, Marantelli G (2003) Emerging disease of amphibians cured by elevated body temperature. Dis Aquat Org 55:65-67 PubMed

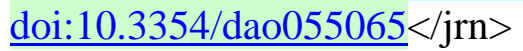

$<$ jrn>Woodhams DC, Geiger CC, Reinert LK, Rollins-Smith LA and others (2012) Treatment of amphibians infected with chytrid fungus: learning from failed trials with itraconazole, antimicrobial peptides, bacteria, and heat therapy. Dis Aquat Org 98:11-25 PubMed doi:10.3354/dao02429 </jrn>

<jrn> Young S, Speare R, Berger L, Skerratt LF (2012) Chloramphenicol with fluid and electrolyte therapy cures terminally ill green tree frogs (Litoria caerulea) with chytridiomycosis. J Zoo Wildl Med 43:330-337 PubMed doi:10.1638/2011-0231.1</jrn>

Table 1. Average temperature $\left({ }^{\circ} \mathrm{C}\right)$ during the experiments, drug concentration, days of treatment and exposure time, number of replicates of experimental groups and overwintering status (NOW: non-overwintering; OW: overwintering), larval developmental (Gosner) stage and average weight (g) of Alytes obstetricans tadpoles for 14 different experiments with itraconazole (ITZ), thiophanate methyl (TM) and a combination of both (TM+ITZ). ' $3 \mathrm{~d}$ $3 \mathrm{dNO}-3 \mathrm{~d}$ ' means treatment was applied over 3 consecutive days, was stopped for $3 \mathrm{~d}$ and resumed for 3 more consecutive days. NA: not available

$\begin{array}{lllll}\begin{array}{l}\text { Experimental } \\ \text { group ID }\end{array} & \text { Temperature } & \begin{array}{l}\text { Drug } \\ \text { (concentration: \% for } \\ \text { ITZ, } \mathrm{mg} \mathrm{l}^{-1} \text { for TM) }\end{array} & \begin{array}{l}\text { Days of treatment } \\ \text { (exposure time) }\end{array} & \mathrm{N}\end{array} \quad \begin{aligned} & \text { Overwintering stat } \\ & \text { Gosner stage/weig }\end{aligned}$

ITZ.1 18

ITZ.1A

$\operatorname{ITZ}(0.0001)$

$7(5 \mathrm{~min})$ 
ITZ.1C

ITZ.2

ITZ.2A

ITZ.2B

ITZ.3

ITZ.3A

ITZ.3B

ITZ.4

ITZ.4

ITZ.5

ITZ.5

ITZ.6

ITZ.6

ITZ.7

ITZ.7

ITZ.8

ITZ.8A

ITZ.8B

TM.1

TM.1

TM.2

TM. 2

TM.3

TM.3

TM.4

TM.4

TM.5

TM.5A

TM.5B
12.5

ITZ (0.001)

ITZ (0.01)

17

ITZ (0.05)

ITZ (0.05)

17

ITZ (0.03)

3 (10 min)

7 (10 min)

17

ITZ (0.025)

7.7

$\operatorname{ITZ}(0.1)$

18.6

ITZ (0.025)

ITZ (0.015)

18.6

TM (0.6)

15.9

TM (1.2)

20.7

TM (6)

13.5

TM (6)

7.2

7 (5 min)

7 (5 min)

7 (10 min)

7 (10 min)

30

30

3d-3dNO-3d (10 min)

3 (10 min)

$9(9 d)$

$9(9 d)$
15
15

OW $/<26 / 0.6$

OW $/<26 / 0.6$

NOW $/<26 / 0.2$

$\mathrm{NOW} /<26 / 0.2$

TM-ITZ.1

TM-ITZ.1A

TM-ITZ.1B

7.8
$15(15 \mathrm{~d})$

15 (15d)

15 (15d)
TM (9)

TM (12)

15

15

15

$\mathrm{TM}(6)+\operatorname{ITZ}(0.0001) \quad 6 \mathrm{dTM}+3 \mathrm{~d} / 10 \mathrm{minITZ}$

$\mathrm{TM}(6)+\mathrm{ITZ}(0.002) \quad 7 \mathrm{dTM}+7 \mathrm{~d} / 10 \mathrm{minITZ}$

15
15

15

15

20

40

40

20

15

15

OW/26-34/0.95

$\mathrm{NOW} /<26 / 0.2$

$\mathrm{NOW} /<26 / 0.2$

$\mathrm{NOW} /<26 / 0.2$

$\mathrm{NOW} /<26 / 0.48$

OW/26-30/1.15

OW/26-30/1.18

OW/26-30/0.92

OW/26-30/1.59

OW/26-37/1.66

OW/26-34/NA

OW/26-34/NA
OW/26-32/0.89 OW/28-35/1.00 
Fig. 1. (A) Average infection loads (mean $\pm 95 \%$ by the BCa method with 2000 bootstrap replications) and prevalence (mean $\pm 95 \%$ Clopper-Pearson $\mathrm{CI}$ ) before (white columns) and after (black columns) treatments of Alytes obstetricans tadpoles with different concentrations and regimens of itraconazole ( 8 experiments), thiophanate methyl (5 experiments) or a combination of both (1 experiment). Experimental groups are arranged according to the drug concentrations used, in ascending order (see Table 1 for details). (B) Survival (\%) of control (black columns) and experimental (grey columns) animals for the same treatment groups. GE: , NA: data not available when there were no surviving animals at the end of the experiment 